\title{
Erosion processes during non-stationary cavitation of irrigation pumps
}

\author{
$A$ Dzhurabekov ${ }^{1}, S h$ Rustamov $^{1}, N$ Nasyrova $^{2}$, and $J$ Rashidov $^{2 *}$ \\ ${ }^{1}$ JSC "SUVMASH", 13, Kh.Baykaro Street, district Bektemir, Tashkent, Uzbekistan \\ ${ }^{2}$ Tashkent Institute of Irrigation and Agricultural Mechanization Engineers, Tashkent, Uzbekistan
}

\begin{abstract}
The article gives the main results of the study of the dynamics of wear of the working bodies of irrigation pumps, gives the main recommendations as a result of the study of pumping units in the presence of cavitation. The authors consider the cavitation coefficient as the minimum value of this expression, at which the beginning of cavitation is detected. The process of unsteady cavitation is accompanied by many significant effects in which the water flow becomes two-phase, with a corresponding change in its properties, which affects the pump's efficiency. The effect of particle size on the erosion rate is predominant only up to a certain size limit, i.e., 600-800 microns on the blades. After that, the erosion rate increases with a comparatively slower rate. This indicates that the particle size affects the erosion rate only up to a certain particle size.
\end{abstract}

\section{Introduction}

A feature of agriculture in the Republics of Central Asia is the widespread development of machine irrigation. By 2021, the capacity of the main pumping and power equipment that has spent the park (factory) resource amounted to more than $70 \%$ of installed capacity at pumping stations (PS). The definition of "limiting" elements of pump assemblies in changing operating conditions is an extremely urgent task at the beginning of the XXI century.

Long-term operation of worn-out equipment in the conditions of tougher operating conditions leads to accelerated physical deterioration of pump components (impeller, impeller chamber, bearings), the main components, the restoration of which requires complete disassembly with decommissioning for a long period. The weighted average efficiency of the equipment is reduced, technical and economic characteristics are deteriorating.

\section{Materials and Methods}

While designing the components handling slurry, it is necessary to select proper material to increase their service life. Different methods can be used to enhance the surface properties to decrease the erosion wear and increase the service life of components. Heat treatment is

* Corresponding author: jaloliddin.rashidov90@gmail.com 
the best method to increase surface hardness. Martensite structure (which has the highest hardness) can be developed on the component's surface, thus retaining higher toughness from inside. The experiments have been conducted on the steels, and it is found that the erosion rate decrease with increasing hardness by heat treatment of the steels.

\section{Results and Discussion}

Improving the efficiency of the operation of the PS is possible only with systematic scientific and production work aimed at improving the design of equipment and structures, studying local conditions and factors affecting the efficiency and safety of the entire hydraulic complex. Unfortunately, centrifugal and axial pumps used for PS irrigation systems do not consider the specific requirements of irrigation PS, motivating them to be designed for pumping clean water.

Operating experience of centrifugal pumps has shown that their manufacture in an abrasion-resistant design (stainless steel parts) does not reduce the wear rate.

The main type of wear on the impeller chambers of the pump is wear in the area of the axis of rotation of the blades. For the wear of the working surface of the chamber, deep sinks are characteristic. There are cases when the walls of a chamber made of carbon steel completely collapsed. The appearance of even minor irregularities on the working surface entails further sharp, intense destruction.

One way to increase the PS's efficiency is to improve the performance of the units used. Functional violations of the operating modes of the pumps depend on objective and subjective factors $[1,2]$.

For example, with a decrease in the water level downstream, the elevation and suction heights increase, the solid particles in the water stream cause intensive wear of the pump elements, reducing the pump elements' flow, pressure, and efficiency units.

Subjective factors include a static imbalance of the impeller of the pump, violation of the tightness of the flow part of the pump and siphon at the water outlet, a break in the line of the shaft of the unit, misalignment of the axes of the stator and rotor of the motor, improper assembly or damage to the elements of the units. Malfunctions associated with subjective factors are eliminated with the appropriate level of staff knowledge and the quality of repair, installation, and commissioning.

Issues of increasing the operational performance of pumps associated with objective factors require the development of scientifically-based structural, technical and operationaltechnological measures. Replacement of pumps with new, modern, more efficient models will ensure a trouble-free operation of the new pump [3, 4].

A comparative wear test of the impeller variants was carried out on a D2000-21 serial pump under the same operating conditions. To reduce the levels of paddle components of pressure pulsations, it is necessary to take the maximum possible gap between the wheel and the housing and remove the circulation along with the rotor blades. The performance of the new pump with an impeller with a diameter of $D_{\text {im }}=425 \mathrm{~mm}$ showed an efficiency value of $\eta_{\mathrm{H} \%}$ calculated $80.1 \ldots 83.0$, actual $80.7 \ldots 86.4$, deviation $+3.4 \ldots+0.6$. During testing, vibration and noise were not observed $[5,6]$.

The wear-resistant qualities of the tested impellers of different designs were evaluated by comparing the time between failures using the coefficient of relative wear resistance of the impellers (table), which is taken as 1 for a serial wheel. 
Table 1. The coefficients of relative wear resistance of the impellers

\begin{tabular}{|c|c|c|c|c|}
\hline $\begin{array}{c}\text { The number of tested } \\
\text { impellers, pieces }\end{array}$ & $\begin{array}{c}\text { Particle size, } \\
\mathrm{mm}\end{array}$ & $\begin{array}{c}\text { Mass } \\
\text { concentration, } \\
\%\end{array}$ & MTBF, hour & $\mathrm{KH}$ \\
\hline 8 & $2-5$ & $15-20$ & $560-610$ & $2.3-3.05$ \\
\hline 4 & $0.5-2$ & $20-23$ & $620-710$ & $2.7-3.1$ \\
\hline
\end{tabular}

The greatest wear of the working parts of the pumps is caused by cavitation. Three parameters affect the start of cavitation:

a) the hydrodynamic characteristics of the flow;

b) physical and thermodynamic properties of water;

c) characteristics of water pollution that form cavitation centers.

Little attention is paid to the first two factors in studies of the effect of cavitation on the characteristics of hydraulic machines. It is assumed that the pressure inside the cavity or cavitation zone is equal to the vapor pressure. This means that no work must be done to overcome the surface tension forces and that no time is required for the vaporization process. The interaction of these three parameters is expressed in the delay in the time of formation and growth of caverns. The relative importance of this time delay can be estimated by its ratio to the time during which the flow passes through the cavitation zone. The experiments carried out with various materials suggest the following sequence of processes during cavitation erosion [7, 8]. Despite the large number of cavitation bubbles formed on the enclosing surface within 1 second, only one in about 30 thousand takes part in its destruction. A few minutes after the development of cavitation, a small depression or cavity appears in the surface enclosing the flow, the diameter of which, depending on the surface material, varies from 0.05 to $0.25 \mathrm{~mm}$. In the first stages of cavitation erosion, there is no destruction and removal of particles of the material; it only deforms under the influence of cavitation "shocks." Subsequently, its destruction begins. As soon as the destruction of the surface has begun, its intensity increases extremely rapidly. However, far from all theories associate cavitation erosion with the formation and destruction of cavitation bubbles. The authors suggest that cavitation bubbles filled with liquid vapor do not collapse but only shrink to the smallest size $[9,10]$.

To assess the possibility of cavitation in the flow, the cavitation coefficient $\sigma$ obtained from the Bernoulli equation is used

$$
\frac{2}{\rho \vartheta_{1}^{2}}\left(p_{1}-p_{\min }\right)-\frac{2 g}{\vartheta_{1}^{2}} \mathrm{~A}_{c}=\frac{\vartheta_{\max }^{2}}{\vartheta_{1}^{2}}-1
$$

where Ac is the work of the flow against resistance forces per $1 \mathrm{~kg}$ of water; is the maximum flow rate corresponding to $p_{\text {min }}$; - flow rate at a distance from the cavitating section; $p_{\min }$ is the minimum pressure corresponding to the onset of cavitation at a pressure $[11,12]$.

When cavitation begins, the condition must be met

$$
\frac{\vartheta_{\max }^{2}}{\vartheta_{1}^{2}}-1=\sigma_{\mathrm{H}}
$$

In this case, the cavitation coefficient 


$$
\sigma_{\mathrm{H}}=\frac{2}{\vartheta_{1}^{2}}\left[\left(p_{1}-p_{\min }\right) \rho^{-1}-g \mathrm{~A}_{c}\right]
$$

If the work of the resistance forces is not taken into account, the expression for the cavitation coefficient, regardless of the stage of its development, will have the form

$$
\sigma=\frac{2\left(p_{1}-p_{\min }\right)}{\rho \vartheta_{1}^{2}}
$$

Based on equations (2) and (1), the authors of the cavitation coefficient are taken into account as the minimum value of this expression, at which only the beginning of cavitation is detected. Therefore, it should be called the coefficient of initial cavitation.

The cavitation process in the flow, especially during non-stationary cavitation, is accompanied by many significant effects. First of all, the flow of water becomes two-phase, with a corresponding change in its properties, which affects the pump's efficiency.

Flow rate is an important parameter that causes wear. The effect of flow rate on erosion is most dominant. The present case flow rate has been varied from 8 litres/s to18 litres/s (Fig.1,a).

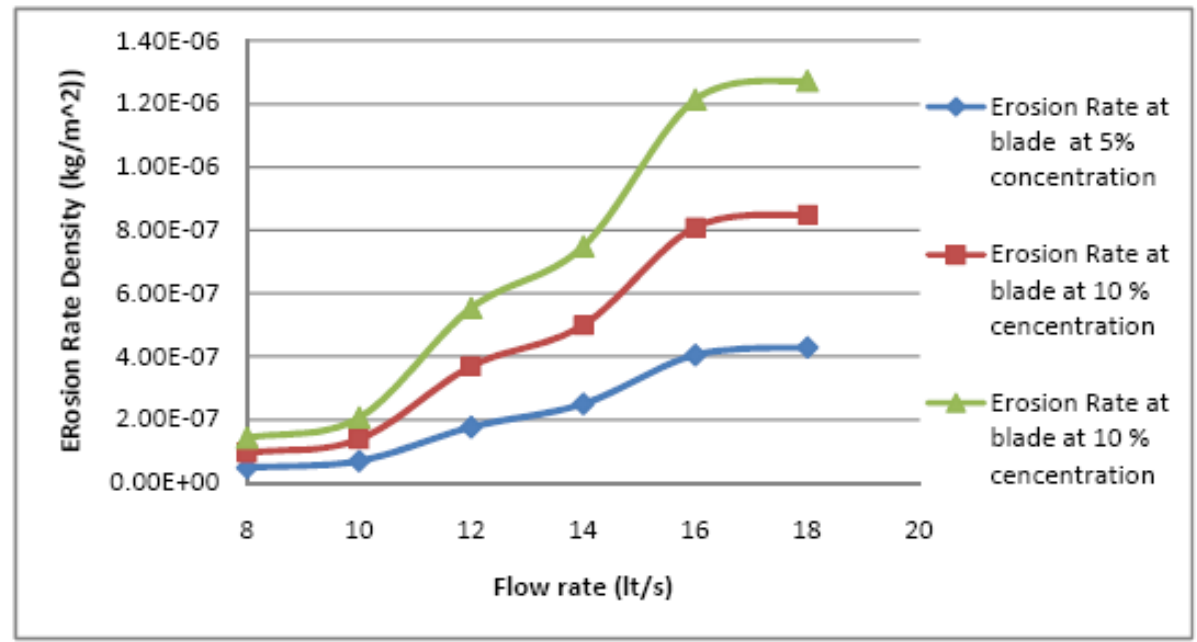

Fig. 1. (a) Erosion rate vs. flow rate at different concentrations on blade

The pattern of increase in erosion rate is nearly the same for $5 \%, 10 \%$, and $15 \%$ concentration. And there is a linear increase in erosion rate with flow rate. At low flow rates, the effects are negligible, but as the flow rate increases, the erosion rate increases.

Effect of speed on the erosion rate on blade and hub $[13,14]$. As revolutions per minute at which impeller rotates increase, the force with which slurry strikes the impeller increases, which in turn increases the erosion rate. The graphs show that the wear is more at the blades than at the hub. In the case of the blade, there is a linear increase in erosion rate concerning increasing in speed. Up to $1400 \mathrm{RPM}$, there is a gradual increase in erosion rate, but it increases more rapidly above $1500 \mathrm{rpm}$. Similarly, there is a gradual increase in the erosion rate density of hub at a lower speed, but above 1700 RPM, there is a sudden increase in the erosion rate. The trends at $5 \%, 10 \%$ and $15 \%$ concentration are nearly same 
(Fig.1,b). However, there is very less effect of concentration on erosion rate density. It justifies that the concentration has a negligible effect on erosion at normal speed.

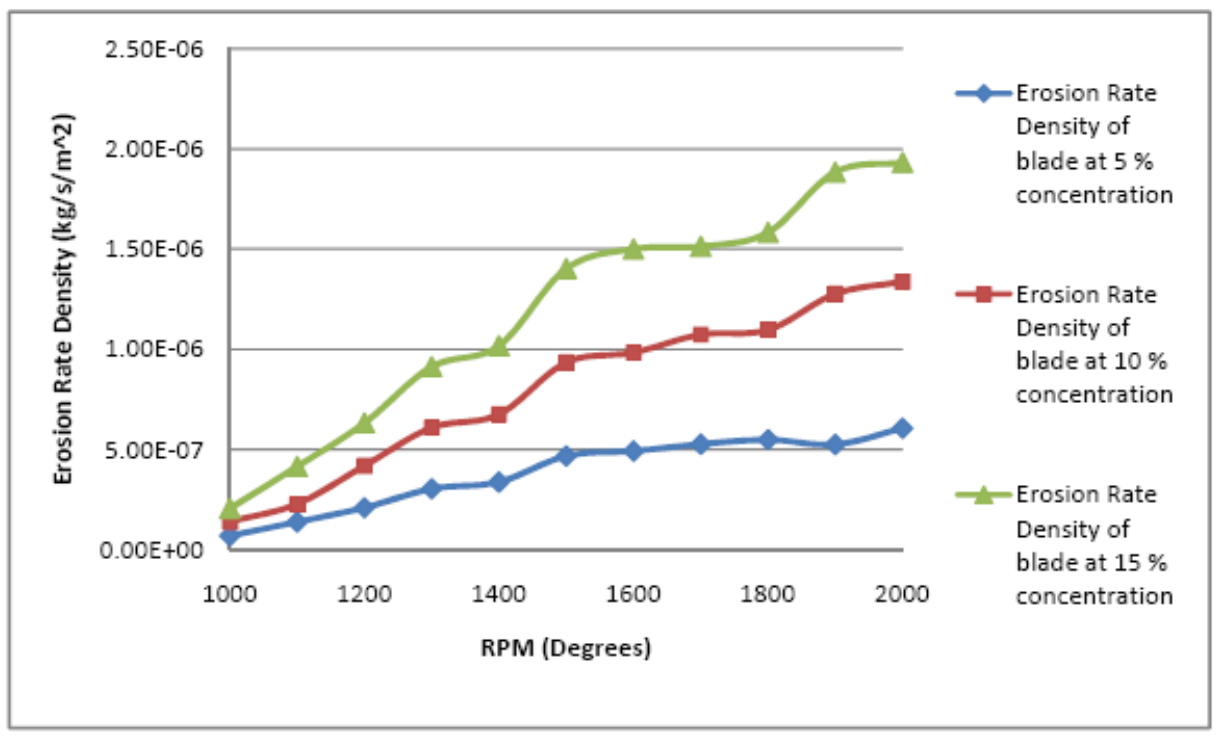

Fig. 1. b- Erosion Rate vs. Speed at different concentrations on blade

The erosion rate can be calculated as:

Erosion Rate $($ grams $)=$ Erosion rate density $\cdot$ surface area $\cdot$ time

$$
\text { Erosion rate }(\text { grams })=\frac{\mathrm{kg}}{s m^{2}} \times m^{2} \times s \times 1000
$$

Suppose erosion rate density for at 16 litre/s at $10 \%$ concentration is $8.08879 \mathrm{E}-7 \cdot$ Area of blade time $\cdot 1000$

For 100 hours of operation, material eroded in grams is

$8.08879 \mathrm{E}-7 \cdot 0.0128465 \cdot 100 \cdot 3600 \cdot 1000$

$3.740855 \mathrm{gm}$

When cavitation occurs in pumping units, their efficiency decreases, which is proportional to the cavitation coefficient $\sigma$ :

$$
\eta=\frac{\sigma 2 g H}{v_{2}^{2}}-\aleph
$$

where $\mathrm{H}$ is the pressure; $v_{2}$ is flow rate; $\aleph$ is coefficient of resistance.

Cavitation prevents an increase in the number of revolutions of the pumps and an increase in the transmitted powers, causes vibration of the parts and reduces the bearing capacity of the pump bearings. However, cavitation is most harmful through its wear and tear. Cavitation in the pumps is explained by the formation of discontinuities in those places where the pressure decreases to saturated vapor pressure at a given temperature, and water boils rapidly with the formation of vapor bubbles, which quickly decrease after passing to the high-pressure zone and the exhaustion of kinetic energy [15-26].

As it develops due to the formation of cavitation bubbles, the active flow in the interblade channels of the impeller increases its cross-section, gradually displacing the vortex 
zone [27-37]. Immediately before the disruption of the pump mode (when the suction pressure approaches the critical pressure of the disruption of the pump mode), the vortex zone disappears completely - the inter-blade channels of the impellers and the inlet section are completely filled with the active flow. These phenomena were tested on the impellers of the PS "Narpay" from various materials from cast iron (a) to stainless steel (b, Fig. 2). Figure 1 shows the damaged surfaces of the edges of the pump blades. The depth of the shells reached 4-5 mm. The operating time was 2200 hours.

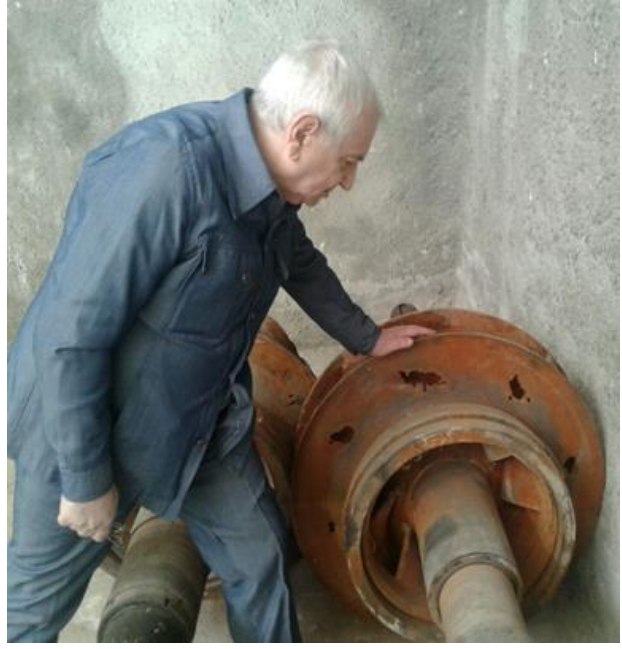

a)

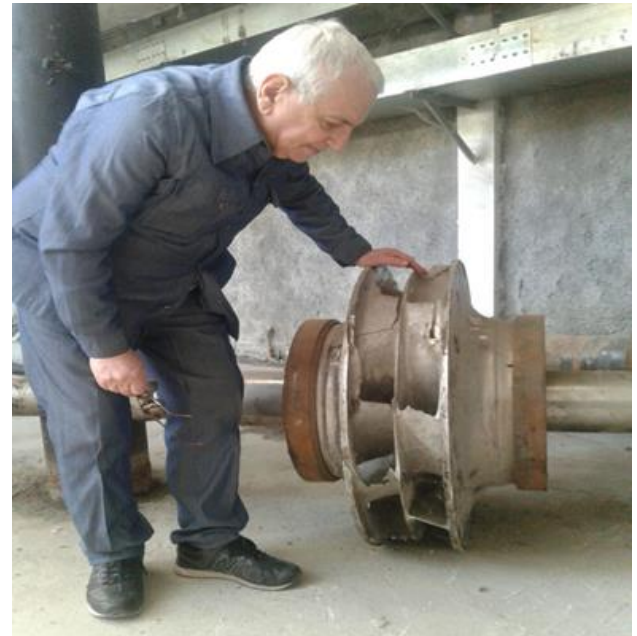

b)

Fig. 2. Analysis of cavitation wear of the pump SPNP80-700SI CD

a) Impeller - cast iron CЧ 20, b) Steel $\mathrm{C}_{\Gamma}-12 \%$; $\mathrm{Ni}-0.16 \%$; Mo - $0.35 \%$

Damage to the working bodies of the PS Charkhin is shown in Fig. 3.
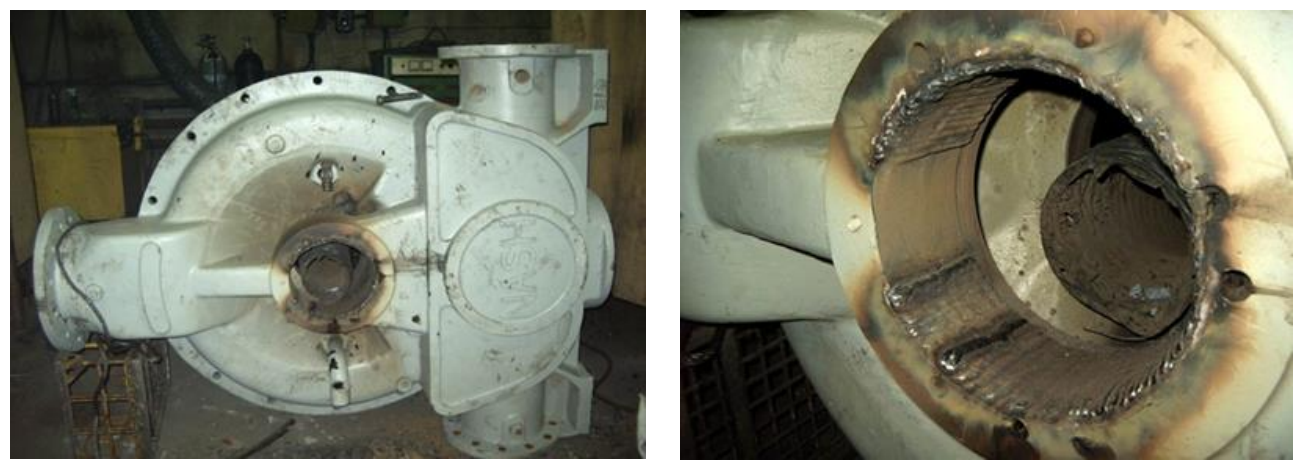

Fig. 3. Depreciation of the working bodies of the centrifugal pump PS "Charkhin"

The authors plan to continue a set of experimental and theoretical studies on creating an optimal pump design for large irrigation water plants in Uzbekistan.

\section{Conclusions}

1. Increasing flow rate causes a sharp decrease in pressure which can cause cavitation on the blade's surface (Figure1, a). The effect of particle size on the erosion rate is 
predominant only up to a certain size limit, i.e., $600-800$ microns on the blades. After that, the erosion rate increases with a comparatively slower rate. This indicates that the particle size affects the erosion rate only up to a certain particle size $[19,20]$.

2. The effect of wear is more at the leading edge than at the trailing edge of blades. So selecting the optimized inlet blade angle can play a major role in reducing erosion wear and providing smooth flow for fluid.

3. The other affecting design parameters such as inlet blade angle, outlet blade angle, and the number of blades can be changed to see the effect of erosion rate. An optimized design could be developed which will have minimum erosion on the impeller.

4. The scope of future work on this topic is very vast. A lot of work can be done in this field. Better designs and improved materials can increase the life of pumps to several more hundred hours.

\section{References}

1. Glovatskiy O.Ya., Nasyrova NR, Bekchanov F.A. Improving the efficiency of operation of pumping stations of irrigation systems // Scientific and practical journal "Ways to improve the efficiency of irrigated agriculture" - Novocherkassk, No. 4 (68), -pp.54-58, (2017)

2. 2. A.I.Dzhurabekov, Sh.R.Rustamov, O.Ya. Glovatsky Mechanism of cavitation and hydroabrasive wear of centrifugal pumps of irrigation pumping stations // Collection of scientific works, SIC ICWC of Central Asia, - pp.153-159, Tashkent, (2017)

3. Rustamov Sh.R., Nasirova N.R. Constructive peculiarities of modernized centrifugal pump // European science review, № 3-4, Vienna. pp-278-280, (2018)

4. Saparov A.B., Glovatsky O.Ya., Nasyrova N.R. Study of modification of the impeller of reversible units in the presence of cavitation // Collection of scientific articles of the XVI scientific-practical conference of young scientists and masters "Modern problems in agriculture and water management", - pp.343-347, - Tashkent, (2017)

5. O.Ya.Glovatsky, Ergashev R.R., Rustamov SH.R. Improvement to usages and studies large pumping station / Monograph LAP LAMBERT Academic Publishing. P.170, Saarbruken-(2013)

6. O.Glovatskiy, T. Djavburiyev, Z. Urazmukhamedova, A. Gazaryan, F.Akhmadov Interconnection of influent channel and pumping station units // XXII International Scientific Conference on Advanced in Civil Engineering / construction the formation of living environment, pp.18-21, April (2019)

7. F.Bekchanov, R.Ergashev, T.Mavlanov, O.Glovatskiy Mathematical model of vibrating air pump unit // XXII International Scientific Conference on Advanced in Civil Engineering / construction the formation of living environment, pp.18-21, April (2019)

8. Zhao H.K, Yabuki A,Matsumura M ,Takahashi,T and Yamamoto M, "Slurry erosion properties of ceramic coating", Wear,Vol. 233-235, pp 608-614,(1999)

9. Anders Sellgren, Addie Graeme and Yu Wi-Chung, "Effects of nonnewtonian mineral suspensions on the performance of centrifugal pumps", Mineral Processing and Extractive Metallurgy Review, Vol20:1, pp 239-249, (1999)

10. Lee S. Y., Dimenna R. A., and Duignan M. R. 2001, "Designing a scaled erosion test with CFD methods", U.S. Department of EnergyWSRC-MS-2001-00500.

11. Gandhi B.K, Singh S. N., Seshadri V., "Performance characteristics of centrifugal slurry pumps", Journal of Fluids Engineering, Vol. 123, pp 271-280, (2001)

12. Hawthorne H.M., "Some Coriolis slurry erosion test developments", Tribology International, Vol. 35 , pp.625-630, (2002) 
13. O.Glovatskiy, T.Djavburiyev, Z.Urazmukhamedova, A.Gazaryan, F.Akhmadov Interconnection of influent channel and pumping station units XXII International Scientific Conference on Advanced in Civil Engineering April 18-21 2019 Construction the formation of living environment, Tashkent, (2019)

14. Svoboda, D.G., Ivanov, E.A., Zharkovskii A.A. Influence of the Geometric Parameters of the Impeller of a Free-Vortex Pump on the Energy and Cavitation Characteristics of the Pump Chemical and Petroleum Engineering, Springer US, Vol. 54, Nos. 9-10, January, 2019, pp. 673-680 DOI: 10.1007/s10556-019-00532-w.

15. Nasrulin A.B., Zhuraev S.R., Saidov F.S. Study of the influence of hydrological and hydraulic parameters on the operating mode of pumping stations. Republican collection of scientific papers, pp.302-306, Tashkent (2018)

16. E.Kan, M.Mukhammadiev, N.Ikramov. Methods of regulating the work of units at irrigation pumping stations. IOP Conference Series: Materials Science and Engineering, Volume 869, (2020) 042009.

17. Borshev, I., Ivanov, E., Zharkovskii A.A., Donskoy, A., Klyuyev, A. Assessment of acoustic and pulsation characteristics of centrifugal pumps (2019) E3S Web of Conferences, 91, article № 07006 DOI:10.1051/e3sconf/20199107006.

18. D. Bazarov, B. Norkulov, B. Obidov, B. Nazarov Experience of employment of computational models for water quality modeling E3S Web Conf., 97 (2019) 05030. DOI: https://doi.org/10.1051/e3sconf/20199705030/.

19. M. Mukhammadiev, A. Nasrulin, A. Mukolyants, D. Ergasheva A complexly method of GIS technologies and optimization models used in the development of environmentally acceptable modes of operation of hydraulic and hydropower facilities in Uzbekistan International Scientific Conference Mathematical Modelling and Methods of Structural Analysis 2019 13th-15th November 2019 Moscow State University of Civil Engineering (MGSU). Moscow, Russia http://www.mmsa2019.org/ IOP Conf. Series: Journal of Physics: Conf. Series 1425 (2020) 012132 DOI: 10.1088./1742-6596/1/0121132.

20. Mukhammadiev M, Klichev Sh Use of Pumped Storage Hydroelectric Power Plants in Uzbekistan Applied Solar Energy ( ISSN 0003-701X, Vol. 54, No. 6) pp.68-71. (2018)

21. Glovatsky, O., Ergashev, R., Nasirova, N., Kholbutaev, B., Khusanbayeva, K. Estimation of the forecast of pump ready rate for reclamation systems, IOP Conference Series: Materials Science and Engineering, 1030(1), 012115, (2021)

22. Ergashev, R., Ismoilov, N., Nasirova, N., Khusanbayeva, K., Nazarov, O. Technology of water supply to water inlets of pumping stations, IOP Conference Series: Materials Science and Engineering, 1030(1), 012156, (2021)

23. Ergashev, R., Azizov, O., Dehkanova, N., Bozorov, A. Development of energy-saving modes of irrigation pump stations, IOP Conference Series: Materials Science and Engineering, 883(1), 012017, (2020)

24. Ergashev, R., Bekchanov, F., Akmalov, Sh., Shodiev, B., Kholbutaev, B. New methods for geoinformation systems of tests and analysis of causes of failure elements of pumping stations, IOP Conference Series: Materials Science and Engineering, 883(1), 012015, (2020)

25. Bekchanov, F., Ergashev, R., Mavlanov, T., Glovatskiy, O. Mathematical model of vibrating air pump unit, E3S Web of Conferences, 97, 05045, (2019)

26. Glovatskii, O.Ya., Ergashev, R.R., Bekchanov, F.A., Sharipov, S.M. Hybrid installations in pumping stations based on the use of renewable energy sources, Applied Solar Energy (English translation of Geliotekhnika), 48(4), pp. 266-268, (2012) 
27. Bazarov D., Vatin N., Obidov B., and Vokhidov O. Hydrodynamic effects of the flow on the slab of the stand in the presence of cavitation. IOP Conf. Ser. Mater. Sci. Eng. 1030, 012110 (2021).

28. Bazarov D., Markova I., Norkulov B. and Vokhidov O. Hydraulic aspects of the layout of head structures during water intake from lowland rivers. IOP Conf. Ser. Mater. Sci. Eng. 1015, 012041 (2021).

29. Bazarov D., Markova I., Sultanov S. and Kattakulov F. Dynamics of the hydraulic and alluvial regime of the lower reaches of the Amudarya after the commissioning of the Takhiatash and Tuyamuyun hydrosystems. IOP Conf. Ser. Mater. Sci. Eng. 1030, 012110 (2021).

30. Bazarov D. and Vokhidov O. Extinguishing Excess Flow Energy in Spillway Structures. In book: Proceedings of EECE 2020, LNCE 150, pp. 535-545, (2021) DOI: 10.1007/978-3-030-72404-7_52

31. Bazarov D., Markova I., Norkulov B., Isabaev K., Sapaeva M. Operational efficiency of water damless intake. IOP Conf. Ser. Mater. Sci. Eng. 869(7), 072051, (2020)

32. Krutov A., Choriev R., Norkulov B., Mavlyanova D. and Shomurodov A. Mathematical modelling of bottom deformations in the kinematic wave approximation. IOP Conf. Ser. Mater. Sci. Eng. 1030, 012147 (2021).

33. Krutov A., Norkulov B., Uljaev F., and Jamalov F. Results of a numerical study of currents in the vicinity of a damless water intake. IOP Conf. Ser. Mater. Sci. Eng. 1030, 012121 (2021).

34. Krutov A., Norkulov B., Mavlyanova D. Simulation of spreading of non-conservative passive substances in water bodies. IOP Conf. Ser. Mater. Sci. Eng. 883(1), 012028 (2020)

35. Krutov A., Norkulov B., Nurmatov P., Mirzaev M. Applicability of zero-dimensional equations to forecast nonconservative components concentration in water bodies. IOP Conf. Ser. Mater. Sci. Eng. 883(1), 012028 (2020)

36. Krutov A., Norkulov B., Artikbekova F., Nurmatov P. Optimal location of an intake at a reservoir prone to salt diffusion. IOP Conf. Ser. Mater. Sci. Eng. 869(7), 072020, (2020)

37. Shokirov B., Norkulov B., Nishanbaev Kh., Khurazbaev M., Nazarov B. Computer simulation of channel processes. E3S Web of Conferences, 97, 05012, (2019) 